\title{
The role of interagency collaboration in facilitating receipt of behavioral health services for youth involved with child welfare and juvenile justice
}

\author{
Emmeline Chuang ${ }^{a},{ }^{*}$ and Rebecca Wells ${ }^{b}$ \\ a Department of Health Policy and Management, Gillings School of Global Public Health, University \\ of North Carolina at Chapel Hill, United States. emchuang@email.unc.edu \\ b Department of Health Policy and Management, Gillings School of Global Public Health, University \\ of North Carolina at Chapel Hill, United States. rswells@email.unc.edu
}

\begin{abstract}
Unmet need for behavioral health care is a serious problem for crossover youth, or those simultaneously involved with the child welfare and juvenile justice systems. Although a large percentage of crossover youth are serious emotionally disturbed, relatively few receive necessary behavioral health services. Few studies have examined the role of interagency collaboration in facilitating behavioral health service access for crossover youth. This study examined associations for three dimensions of collaboration between local child welfare and juvenile justice agencies jurisdiction, shared information systems, and overall connectivity - and youths' odds of receiving behavioral health services. Data were drawn from the National Survey of Child and Adolescent WellBeing, a national survey of families engaged with the child welfare system. Having a single agency accountable for youth care increased youth odds of receiving outpatient and inpatient behavioral health services. Inter-agency sharing of administrative data increased youth odds of inpatient behavioral health service receipt. Clarifying agency accountability and linking databases across sectors may improve service access for youth involved with both the child welfare and juvenile justice systems.
\end{abstract}

\section{Keywords}

collaboration; child welfare; juvenile justice; behavioral health

\section{Introduction}

There is significant overlap in the population of youth served by the child welfare and juvenile justice systems (Malmgren \& Meisel, 2004; Polivka \& Clark, 1994). Children who have been abused and/or neglected are at elevated risk of becoming delinquent (Thornberry, Huizinga, \& Loeber, 2004; Widom, 1989; Wiig \& Widom, 2003), and many youth in the juvenile justice

\footnotetext{
(C) 2010 Elsevier Ltd. All rights reserved.

*Corresponding author. Department of Health Policy and Management Gillings School of Global Public Health University of North Carolina at Chapel Hill Campus Box 7411 McGavran-Greenberg Hall Chapel Hill, NC 27599-7411 Telephone: (858)-774-6586.

Publisher's Disclaimer: This is a PDF file of an unedited manuscript that has been accepted for publication. As a service to our customers we are providing this early version of the manuscript. The manuscript will undergo copyediting, typesetting, and review of the resulting proof before it is published in its final citable form. Please note that during the production process errors may be discovered which could affect the content, and all legal disclaimers that apply to the journal pertain.
} 
system wind up entering the foster care system as well. "Crossover youth," or youth who are involved with both the child welfare and juvenile justice systems, are particularly at risk for future engagement with the criminal justice system. Although the overall percentage of crossover youth within the juvenile justice system is small (Tjaden \& Thoennes, 1992), these youth remain longer in the juvenile justice system and are more likely to recidivate than those not involved with child welfare (Halemba, Siegel, Lord, \& Zawacki, 2004; Morris \& Freundlich, 2004; Ryan, Herz, Hernandez, \& Marshall, 2007).

Provision of behavioral health and social services such as housing or mentorship programs increases the likelihood that youth involved with the child welfare and/or juvenile justice systems will successfully transition back to school, work, and the community (Baltodano, Mathur, \& Rutherford, 2005; Glascoe, 2000; Jonson-Reid \& Barth, 2000; Pullmann et al., 2006). Prevalence estimates indicate that between $40-86 \%$ of the youth involved with either child welfare or juvenile justice are seriously emotionally disturbed (Barnes et al., 2005; Burns et al., 2004; Cocozza \& Skowyra, 2000; Leslie et al., 2005). Youth with untreated behavioral problems are at higher risk of future delinquency, making the social consequences of unmet service needs very high (Coleman \& Jenson, 2000; Jonson-Reid, 2002; Kortenkamp \& Ehrle, 2002; Vander Stoep, Evens, \& Taub, 1997).

Unfortunately, only a small percentage of youth in the child welfare and juvenile justice systems who need behavioral health services receive them (Burns et al., 2004; SAMHSA, 2008). Research shows that referral rates from child welfare and juvenile justice to behavioral health treatment are significantly lower than even conservative estimates of need and that unmet service need is particularly high for crossover youth (Breda, 2001; Glisson, 1996). Part of the problem is that these children and youth are involved with multiple agencies; thus, ensuring service receipt requires coordination across the agencies with which they are involved (Darlington, Feeney, \& Rixon, 2005; Greenbaum et al., 1996; Howell, Kelly, Palmer, \& Mangum, 2004).

Coordination between agencies is challenging (Darlington et al., 2005; Ross, 2009; Stiffman, Chen, Elze, Dore, \& Cheng, 1997). Staff in child welfare and juvenile justice agencies face many barriers to cooperation, including different organizational priorities, confusion over how services should be funded and who has jurisdiction over the youth, and difficulty in tracking cases across organizations (Conger \& Ross, 2006; Ryan et al., 2007; Sedlak et al., 2006). These barriers can result in negative outcomes for youth. For example, Glisson \& Hemmelgarn (1998) found that efforts to coordinate services between public child serving agencies including child welfare and juvenile justice - in 24 Tennessee counties were negatively associated with the quality of services provided to children, a finding they attributed to a diffusion of responsibility for case management.

Human services research suggests that interagency collaboration, a process involving the exchange of information and/or resources between agencies, can help agencies ensure that youth involved with multiple sectors receive necessary services (Colby \& Murrell, 1998; Hurlburt et al., 2004). Cottrell, Lucey, Porter, et al. (2000) found that a multifaceted collaborative initiative between child welfare and mental health agencies resulted in faster access to mental health for children and adolescents involved with both systems. Bai, Wells, $\&$ Hillemeier (2009) found that a greater number of inter-organizational arrangements between child welfare and mental health agencies was associated with improved children's mental health outcomes.

Evidence also suggests that the courts can play an important role in facilitating access to behavioral health services for families involved with the child welfare system (Fedoravicius, McMillen, Rowe, Kagotho, \& Ware, 2008; Rittner, 2000). However, while a number of 
collaborative efforts between child welfare and juvenile justice agencies have been attempted (Kamradt, 2000; Ross, 2009), there is currently only limited empirical evidence as to whether collaboration can help agencies facilitate service access for crossover youth.

The current study contributes to the literature by using a national sample of children involved with the child welfare system to examine how interagency collaboration between child welfare and juvenile justice agencies is associated with the likelihood that crossover youth receive necessary behavioral health services. Consistent with literature suggesting that collaboration is a multidimensional construct (Gray, 2000; Thomson, Perry, \& Miller, 2007), this study examined associations between three different dimensions of collaboration and youths' service receipt. Specific dimensions of collaboration examined were: (a) jurisdiction, or the establishment of agency responsibility for dually involved youth; (b) shared information systems through which collaborative efforts could be implemented; and (c) overall connectivity, or the total number of different ways that agencies worked together.

\subsection{Jurisdiction}

Jurisdiction is an important dimension of collaboration because it involves the development of rules about who is eligible to make decisions, which actions are allowed or constrained, and what information needs to be provided (Ostrom, 1990). Clarifying agency accountability is particularly important for crossover youth. Although a few states end child welfare involvement once youth enter the juvenile justice system, the majority of states allow for concurrent jurisdiction (Herz, Krinsky, \& Ryan, 2006). Child welfare and juvenile justice agencies with concurrent jurisdiction can experience tensions related to appropriate roles and responsibilities and differing organizational timelines that make each reluctant to assume primary responsibility for crossover youth (Bilchik \& Stagner, 2009; Ross, 2009; Ryan et al., 2007). Consequently, when accountability for youth has not been clearly established, youth may be less likely to receive necessary services (Ross, 2009). For example, Conger \& Ross (2006) found that communication gaps between agency staff meant that crossover youth were more at risk of losing foster care and behavioral health service placements than youth not involved with child welfare. Designating a single agency as accountable for these youth could clarify accountability and was therefore hypothesized to increase crossover youths' odds of receiving necessary behavioral health services.

\subsection{Shared information systems}

Shared information systems allow participating agencies to communicate and monitor each others' activities in relation to their respective roles and responsibilities (Bardach, 1998; Thomson et al., 2007). This dimension of collaboration is important because research has demonstrated that discrepant information-gathering procedures and administrative databases across agencies can leave staff unaware of youths' involvement with other agencies (Sedlak et al., 2006; Young, Boles, \& Otero, 2007). In recent years, concern over the difficulty of tracking cases between incompatible organizational filing systems have led some agencies to develop multi-sector administrative databases (Jonson-Reid \& Barth, 2000; Sedlak et al., 2006). A linked database could reduce the time and effort required to track a case among different organizations, increase staff awareness of whether youth have received necessary services, and subsequently facilitate coordinated service delivery. In the current study, shared information systems, and specifically greater sharing of administrative data between the child welfare and juvenile justice system, was hypothesized to increase crossover youths' odds of receiving behavioral health services.

\subsection{Connectivity}

Many child welfare and juvenile justice agencies have established a number of different types of inter-organizational arrangements such as joint decision-making, cross-training of staff, or 
joint budgeting (Hunter, 2003). These arrangements are all expected to help agencies facilitate service access for crossover youth. For example, joint decision-making could raise staff awareness of services that youth are receiving at other agencies (Hunter, 2003; Kamradt, 2000). Cross-training might make staff more cognizant of other agencies' perspectives and priorities and also build positive relationships between individuals (Altshuler, 2003; Drabble, 2007). Joint budgeting could help address agency concerns over how services will be funded and reduce "turf wars" around funding streams (Goldstrom, Jaiquan, Henderson, Male, \& Manderscheid, 2001). Social network research suggests that having a number of different interorganizational arrangements is reflective of stronger overall collaboration between agencies (Granovetter, 1973; Ibarra, 1995); agencies with these connections interact in a variety of ways and subsequently develop more trusting and reliable relationships. Greater connectivity between agencies, also referred to in the social networks literature as multiplexity, has been positively associated with service outcomes in other sectors (Brass, Butterfield, \& Skaggs, 1998; Granovetter, 1973; Ibarra, 1993), and was hypothesized to improve crossover youths' odds of receiving necessary behavioral health services as well.

\section{Methods}

\subsection{Data and sample}

Data on youths' behavioral health service receipt were drawn from the Child Protective Services (CPS) cohort of the National Survey of Child and Adolescent Well-Being (NSCAW), the only national study of children in the U.S. child welfare system (Dowd et al., 2004). NSCAW was funded by the Administration for Children and Families within the U.S. Department of Health and Human Services and was carried out by Research Triangle Institute (RTI) International. A complex sampling design involving two stages of stratification was employed. The first level was comprised of eight strata each representing a large state plus a ninth stratum of 28 additional states. Across all nine strata, a total of 92 county CPS agencies were the primary sampling units from which children were sampled. The initial NSCAW Child Protective Services cohort included 4,080 children and youth who were referred and investigated for maltreatment between October 1999 and December 2000 and subsequently received any services - including case management, family support, and/or social services - from the child welfare agency.

Assessments of child context and well-being were conducted through interviews with each child, his or her current caregiver, and the child welfare caseworker at baseline (Wave 1, with interviews conducted between October 1999 and December 2000), 12 months (Wave 2), 18 months (Wave 3), and 36 months (Wave 4) after becoming involved with the child welfare system. A subsequent fifth wave was collected at 48 months, but these data were omitted from the current analyses because of the significantly higher attrition in response rates as youth within the sample emancipated.

Current caregivers, whether permanent or foster, were asked about children's service receipt in all four waves. Directors of 86 of the 92 child welfare agencies in the NSCAW sample were interviewed at baseline (Wave 1) about agency management practices and policy contexts, including the existence of formal, collaborative agreements with other agencies such as juvenile justice. Data on agency accountability for crossover youth were obtained from the NSCAW-affiliated Caring for Children in Child Welfare (CCCW) study, a telephoneadministered key informant interview of NSCAW contact persons in 89 of the 92 child welfare agencies (Kolko, Herschell, Costello, \& Kolko, 2009). Using an identical sampling frame as that of NSCAW, and fielded between 2000 and 2001, CCCW identified key informants within each county, who provided detailed information regarding the organization of child welfare agency services. Additional details regarding the design and fielding of $\mathrm{CCCW}$ are available elsewhere (e.g. Libby et al., 2007). 
Information on the extent of data sharing between the child welfare and juvenile justice data systems was obtained from the Child Welfare League of America National Data Analysis System (NDAS). Contextual information on local provider availability and child welfare agencies' urban-rural location was obtained from the 2000 Area Resource File (ARF), the National Survey of Substance Abuse Treatment Services (NSSATS), and data on county-level mental health shortages (Thomas, Ellis, Konrad, Holzer, \& Morrissey, 2009). These data were merged with NSCAW data using county-level identifiers by RTI International upon request.

Given the study's focus on how collaboration between child welfare and juvenile justice systems was associated with behavioral health service receipt, the study sample was restricted to children and youth who (1) needed behavioral health services, and (2) were involved with the juvenile justice system. Only individuals aged six years or older at baseline were included in this categorization, to account for children who would be eligible for juvenile justice involvement by Wave 4, or 36 months after initial child welfare involvement. Application of these inclusion criteria yielded a sample of 407 youth within 75 agencies.

Of these 407 youth, 330 were located in child welfare agencies in which directors were interviewed about agency management practices. Additional information about data sharing and child welfare agency accountability was available for 219 of these 330 cases. Listwise deletion for item missingness resulted in a final analytic sample of 178 youth located in 51 agencies for models predicting mental health service receipt, and 173 youth located in 51 agencies for models predicting substance abuse treatment.

In an effort to maintain the full sample size of 407 youth, multiple imputation was attempted using the IVEware module within the SAS statistical software (Raghunathan, Solenberger, \& Hoewyk, 2002). However, high imputation-to-imputation variance in estimated values for the collaboration variables indicated an inability to impute values for those variables reliably, despite incorporation of extensive agency-level data in the information matrix. Therefore, the unimputed final analytic samples of 178 and 173 youth for the mental health and substance abuse treatment models respectively were used in the regression analyses.

The sampling weights within NSCAW incorporate differential selection probabilities as well as potential bias resulting from survey non-response and thus should yield nationally representative estimates (Dowd et al., 2004; Little, 1988). However, these weights do not account for item non-response. Weighted t-tests conducted to determine if data were missing at random indicated that youth in the final analytic sample differed from those excluded due to listwise deletion in other model variables in only two areas: being sexually abused ( $21 \%$ of the final analytic sample vs. $8 \%$ of the excluded cases, p-value for t-test $<0.01$ ); and being outof-home at baseline (31\% of the analytic sample vs. $13 \%$ of the excluded cases, $\mathrm{p}$-value for $\mathrm{t}$ test $<0.01)$. Although these differences suggest that youth in the analytic sample might be more at-risk for behavioral health problems than those excluded (e.g. Aarons et al., 2010; Cavaiola $\&$ Schiff, 1988), the weighted t-tests did not indicate significant differences on measures of substance abuse risk or mental health need.

Similarly, child welfare agencies included in the final analytic sample differed from those excluded due to listwise deletion in the percentage of out-of-home youth within the agency (approximately $43 \%$ for agencies in the final analytic sample vs. $20 \%$ in the excluded cases, $\mathrm{p}$-value for t-test $<0.05$ ). While this difference suggests that agencies in the analytic sample could be serving more high-needs youth, there were no significant differences between agencies in the percentage of youth with mental health needs or those at risk of substance use disorders. 


\subsection{Measures}

2.2.1. Need for behavioral health services-Youth were assessed as needing behavioral health services if they met any of the following criteria: (1) a clinical Child Behavior Checklist score ( $>64$ on either the internalizing or externalizing behavior scales) (Achenbach \& Edelbrock, 1983); (2) services caseworker report that the youth had a drug or alcohol abuse problem; or (3) youth self-report of drug or alcohol use indicated medium to high risk of a substance abuse problem. Youth risk for a substance abuse problem was assessed using an ordinal measure developed by Richard Barth's NSCAW Research Group at the UNC School of Social Work and based on the gateway model of adolescent substance abuse (Wagner \& Anthony, 2002). In this measure, youth responses about the frequency of substance use were multiplied by the risk level of each substance and then used to generate a total score of substance abuse risk, with 0 indicating no risk, 1 for low risk, 2 for medium risk, and 3 indicating high risk (Wall \& Kohl, 2007).

2.2.2. Involvement with juvenile justice-Youth were considered either involved or at high risk of involvement with the juvenile justice system if the current caregiver reported that the youth had gone to court for misbehaving - including delinquency, running away, truancy, or other offenses - in any wave, or if the youth reported participating in any delinquent or criminal activities (Elliott \& Ageton, 1980).

2.2.3. Receipt of behavioral health services-Behavioral health service receipt was measured using four variables drawn from an adapted version of the Child and Adolescent Services Assessment (CASA) (Ascher, Farmer, Burns, \& Angold, 1996). These variables are based on current caregivers' - either biological parents or foster caregivers - report of whether the youth received (1) outpatient mental health, defined as attendance at a day treatment program, a mental health or community health center, or receipt of services from private professionals such as a psychiatrist, psychologist, social worker, or psychiatric nurse for a behavioral health problem; (2) inpatient mental health services, defined as receiving treatment at a psychiatric hospital, a psych unit within a hospital, or a hospital medical inpatient unit for a behavioral health problem; (3) outpatient substance abuse treatment, or attendance at a day treatment program or outpatient drug and alcohol clinic; and (4) inpatient substance abuse treatment, defined as receiving treatment from a detoxification unit, an inpatient drug or alcohol unit, or a hospital medical inpatient unit for a substance abuse problem.

2.2.4. Collaboration between child welfare and juvenile justice-Three dimensions of collaboration between child welfare and juvenile justice agencies - jurisdiction, shared information systems, and connectivity - were measured.

Jurisdiction was operationalized as the designation of agency accountability and was measured using two dummy variables based on child welfare administrators' report of whether care for crossover youth was under joint child welfare-juvenile justice control (referent group), child welfare control, or juvenile justice control.

Given the importance of administrative databases to child welfare and juvenile justice agencies, shared information systems was operationalized as the extent to which local child welfare and juvenile justice agencies could access each other's databases. This variable was set to 0 if the child welfare and juvenile justice had separate data systems with no cross-referencing, 1 if they had separate data systems with cross-referencing, and 2 if they had the same data system.

Finally, consistent with measures utilized in previous studies (Bai, Wells, \& Hillemeier, 2009; Hurlburt et al., 2004), connectivity was measured as the number of ties connecting the local child welfare and juvenile justice agencies. This number was based on local child welfare agency directors' reports of whether their agency had the following ties with juvenile justice 
agencies: discussion and information sharing; development of inter-agency agreements and memoranda of understanding; joint planning or policy formulation for service delivery; crosstraining of staff; and joint budgeting or resource allocation.

2.2.5. Control variables-Two agency-level control variables for local service context were included to account for potential confounders of the associations between focal predictors and likelihood of behavioral health service receipt. A dichotomous measure derived from 2000 Area Resource File data indicated whether the agency was located within a non-metropolitan statistical area, and served as a control for rural-urban differences in service provision and as a proxy for organizational size (Beale, 2003). The second variable was used to control for local behavioral health provider availability. For models predicting mental health service receipt, this variable was operationalized as the percentage of unmet mental health need within the county, including that for providers with and without prescription authority (Thomas et al., 2009). While not specific to pediatric providers, this measure does provide an overall indication of potential provider availability within each county. For models predicting substance abuse treatment, the 2000 National Survey of Substance Abuse Treatment Services data were utilized to create a measure of the number of behavioral health providers within the county. This variable was log-transformed in the analyses to accommodate anticipated diminishing returns to scale.

In addition, certain baseline factors known to influence youths' likelihood of receiving behavioral health services and/or involvement with child welfare and juvenile justice were also added as control variables. These factors are: a court order that the youth receive services, which could give youth priority for openings in behavioral health facilities (Rittner, 2000); a mental health or substance use comorbidity, operationalized as including youth with both a clinical CBCL score and a substance abuse problem (Blumberg, Landsverk, Ellis-MacLeod, Ganger, \& Culver, 1996; Greenbaum et al., 1996); sexual abuse (Bagley, Wood, \& Wood, 1994; Beitchman et al., 1992); out-of-home placement (Conger \& Ross, 2006; Courtney, 2000); male gender (Graves, Frabutt, \& Shelton, 2007); age, with older youth being more likely to receive services (Burns et al., 1995); African American race or Hispanic ethnicity (Courtney et al., 1996); and youth health insurance (Glied, Hoven, Moore, Garrett, \& Regier, 1997).

\subsection{Analyses}

NSCAW data have a hierarchical structure, with children, caregivers, and caseworkers nested within child welfare agencies. Consequently, unconditional multilevel models (not shown) were used to examine the degree to which child welfare agency-level factors contributed to the total variance observed in each dependent variable. Results of the unconditional multilevel models indicated that for all of the variables measuring behavioral health service receipt there was a low amount of variance in outcomes due to agency-level factors (2\%-6\%). In addition, the analytic sample contained a relatively modest number of level-2 units (51 child welfare agencies). With unbalanced data such as NSCAW, estimation of coefficients and standard errors in multilevel models rely on large-sample theory. Particularly with binary dependent variables, a small sample of level-2 units can result in biased estimates premised on inaccurate assumptions about variable distributions (Raudenbush \& Bryk, 2002). Given both the modest ICCs and number of level-2 units, all models were therefore analyzed as single-level models, including a post-hoc adjustment to standard errors that accommodated clustering of youth within child welfare agencies (DeLeeuw \& Meijer, 2008).

All analyses were conducted using the Stata 10.0 -svy- module (StataCorp, 2007). The -svymodule permits analysis that accounts for the complex survey design of the data, accommodating probability weights and stratification as well as correlations in outcomes across youth located within the same child welfare agencies. The post-hoc adjustment to 
standard errors utilized within the -svy- module is similar to that used by the robust standard error procedure, differing only by a constant multiplier (DeLeeuw \& Meijer, 2008; StataCorp, 2005). Reflecting the dichotomous nature of the dependent variables, the logistic link function was used in all four regression models.

Power calculations conducted using the Optimal Design software determined that for all key independent variables there was sufficient power to detect a medium effect size (0.5) at a significance level $(\alpha)$ of 0.05 (Spybrook, Raudenbush, Liu, Congdon, \& Martinez, 2008).

Phi tests of bivariate correlation (not shown) did not indicate any problematic collinearity among independent variables within the four analytic models (no correlations >.4). However, there was moderate overlap in the dependent variables related to youth receipt of different types of behavioral health service receipt. Additional models (not shown) were run to determine whether receipt of one type of behavioral health service was associated with youths' likelihood of receiving other such services. Results of these models indicated that youth receiving one type of behavioral health service were more likely to receive a different type of service of the same intensity (e.g. youth receiving outpatient mental health were more likely to receive outpatient substance abuse and vice versa; youth receiving inpatient mental health were more likely to receive inpatient substance abuse treatment, and vice versa). However, receipt of other types of services was non-significant. As the final analytic models include a control variable for youth comorbidity (i.e. need for both mental health and substance abuse services), we concluded that omitting a control variable for youths' receipt of other types of services would not bias model results.

This secondary data analysis was approved by the Institutional Review Board at the lead author's home institution. The original data collection was approved by an Institutional Review Board at RTI International.

\section{Results}

Table 1 provides weighted descriptive statistics for all study measures. Of the children and youth assessed as needing behavioral health services and involved with juvenile justice, approximately $20 \%$ of youth did not receive any behavioral health services, $78 \%$ received outpatient mental health services, $33 \%$ received inpatient mental health services, $14 \%$ received outpatient substance abuse treatment, and $13 \%$ received inpatient substance abuse treatment within three years of entering the child welfare system.

Child welfare agencies were exclusively accountable for the care of approximately $36 \%$ of crossover youth; juvenile justice agencies were accountable for $42 \%$; and $22 \%$ of youth were under joint child welfare - juvenile justice control. Approximately $20 \%$ of child welfare agencies shared at least some administrative data with juvenile justice. Of these agencies, $15 \%$ had separate systems with cross-referencing capabilities; only $5 \%$ of agencies had the same data system. On average, child welfare agencies reported having 3.6 of 5 possible different inter-organizational arrangements with local juvenile justice agencies.

Comparisons of youth under different jurisdictions (i.e. child welfare, juvenile justice, and joint child welfare-juvenile justice control) were also conducted (Table 2). A disproportionate percentage of youth whose care was under joint child welfare-juvenile justice control had substance abuse problems (79\%, compared to 58\% under child welfare control and 52\% under juvenile justice control). However, a smaller percentage of youth under joint control received outpatient substance abuse treatment (10\% received outpatient substance abuse treatment, compared to $15 \%$ for those under child welfare control and $14 \%$ for those under juvenile justice control). None of the youth whose care was under joint child welfare-juvenile justice control received inpatient substance abuse treatment (compared to $7 \%$ under child welfare control and 
$25 \%$ under juvenile justice control). In addition, a smaller percentage of youth whose care was under joint child welfare-juvenile justice control were placed out-of-home at baseline (14\%, compared to $36 \%$ of youth under child welfare control and $34 \%$ under juvenile justice control). Finally, a greater percentage of sexually abused youth were under juvenile justice control (29\%, compared to $15 \%$ under child welfare control and $15 \%$ under joint child welfare-juvenile justice control).

Multiple regression results are shown in Tables 3 and 4. Compared to youth under concurrent child welfare-juvenile justice jurisdiction, youth whose care was under child welfare control had higher odds of receiving outpatient behavioral health services (OR 3.09, $\mathrm{p}<0.05$ for outpatient mental health; OR $6.07, \mathrm{p}<0.05$ for outpatient substance abuse treatment). In the model predicting youth receipt of inpatient substance abuse treatment, joint child welfarejuvenile justice control was a perfect predictor of youths' failure to receive services; consequently, the relative odds of youth under child welfare or juvenile justice control receiving such services was estimated as positive infinity. An additional model (not shown) found that compared to youth under child welfare control, youth under juvenile justice control had higher odds of inpatient substance abuse treatment than youth under child welfare control (OR 5.39, $\mathrm{p}<0.05)$.

Greater sharing of administrative data between local child welfare and juvenile justice agencies was not significantly associated with youth odds of receiving outpatient behavioral health services. However, administrative data sharing was positively associated with youths' odds of receiving both inpatient mental health services $(O R 3.55, \mathrm{p}<0.01)$ and inpatient substance abuse treatment (OR 3.30, p<0.01).

Contrary to our hypothesis, the total number of different arrangements between child welfare and juvenile justice agencies was not significantly associated with any type of service receipt (p>0.05). Additional models (not shown) run to test for the possibility that specific types of inter-organizational arrangements would have more impact than the total number of ties also found non-significant associations with youth receipt of behavioral health services.

Several control variables were also significantly associated with youths' odds of receiving behavioral health services. A court order for youth to receive services increased youth's odds of receiving outpatient mental health services (OR 23.17, $\mathrm{p}<0.001)$ and inpatient substance abuse treatment (OR 5.72, $\mathrm{p}<0.01$ ). Co-morbidity for both a mental health and substance abuse treatment problem reduced crossover youth's odds of receiving outpatient mental health treatment (OR 0.14, $\mathrm{p}<0.05)$ but significantly increased youth odds of receiving outpatient and inpatient substance abuse treatment (OR 13.93, $<<0.05$; OR 38.97, $\mathrm{p}<0.05$ ). Having either private insurance or being self-pay (i.e. no insurance), relative to having Medicaid or other public insurance, was negatively associated with youths' odds of receiving inpatient behavioral health services.

\section{Discussion}

As hypothesized, both designation of single agency accountability and sharing of administrative data were significantly associated with youths' odds of receiving necessary behavioral health services. A disproportionately high percentage of youth whose care was under joint child welfare-juvenile justice control needed behavioral health services; however, youth were significantly more likely to receive both outpatient and inpatient behavioral health services when their care was under single agency control. These findings are consistent with literature suggesting that clarifying agency staff responsibility for youths' care may have an important impact on service outcomes (Siegel \& Lord, 2005). Designating a single agency as accountable for crossover youths' care may facilitate the development of a single, coordinated 
case plan. Staff at the accountable agency may also be more likely to follow up and determine whether youth are receiving necessary services.

The differential findings related to child welfare vs. juvenile justice control were more surprising. Youth whose care was under child welfare agency control had significantly higher odds of receiving outpatient behavioral health services, while youth under juvenile justice control had higher odds of receiving inpatient substance abuse treatment. There are two possible interpretations for the differential findings related to child welfare vs. juvenile justice control. First, in some regions, dual jurisdiction is not permitted by law and the local child welfare and juvenile justice agencies must recommend to the court which status, dependency or delinquency, is in the best interests of the minor and society (Nash \& Bilchik, 2009). In these situations, it is likely that the most seriously disturbed youth - who are also those most likely to need inpatient substance abuse treatment rather than outpatient - will be placed under juvenile justice control rather than child welfare. In the current study sample, similar proportions of youth under child welfare vs. juvenile justice control had mental health and substance abuse problems. However, the NSCAW data did not include an in-depth evaluation of youths' need for outpatient vs. inpatient treatment. Therefore, it is possible the differential findings related to child welfare vs. juvenile justice responsibility reflect youths' different service needs.

Another possible explanation for the difference in findings related to child welfare vs. juvenile control for crossover youths' care is that there are differences between child welfare and juvenile justice agencies that influence youths' odds of receiving services independent of need. The agency in the system the youth entered first often obtains primary responsibility for youths' care. Prior research suggests that youths' behavioral service experiences vary depending on whether their care is under child welfare or juvenile justice control. These variations exist even after controlling for youth attributes and have been attributed to the different philosophies underpinning each system. For example, while juvenile court judges often believe that behavioral health services have value and may support rehabilitation (Breda, 2001; Schwartz, 1989), their focus is generally on correcting the behavior directly responsible for youths' entry into the corrections system rather than long-term resolution of underlying behavioral health problems (Heggeness \& Davis, 2010). In the current sample, this tendency could have been manifested as juvenile justice agencies being more likely to place youth in short-term inpatient substance abuse treatment, such as a detox unit, rather than in longer-term outpatient services. Additional research is needed that more closely examines why crossover youths' service experiences in different systems vary and how these differences may impact long-term outcomes.

The current study's findings related to sharing of administrative data were to some extent consistent with prior evidence suggesting that shared information systems can improve service coordination (Sedlak et al., 2006; Thomson et al., 2007; Young et al., 2007). There were strong, positive associations between child welfare and juvenile justice agencies' sharing of administrative data and youths' odds of receiving inpatient behavioral health services. Associations between agency sharing of administrative data and youth receipt of outpatient services were also positive, but were not statistically significant.

Research has shown that crossover youth require a more intense array of services and supports than youth involved with only one system (e.g. Herz \& Ryan, 2008). Many of these youth are seriously emotionally disturbed; therefore, the significant associations between agency sharing of administrative data and youth receipt of inpatient services may be reflective of actual youth service needs. However, it is also possible that staff aware of youths' involvement with other agencies may perceive such youth as more high-risk and subsequently be more likely to place them in inpatient services. Previous studies have found that agency staff perceive crossover 
youth as "higher risk," and that this perception can influence both the processing of youths' cases and their subsequent placements (Morris \& Freundlich, 2004; Ross, 2009). For example, Ryan et al. (2007) found that even after controlling for youth attributes such as age, gender, race, and type of offense, crossover youth were significantly less likely to receive probation than delinquent youth not involved with child welfare. Such perceptions and the tendency to keep these youth in detention could influence the types of behavioral health services crossover youth receive more than any actual differences in service need.

Contrary to most prior research examining inter-organizational relationships between child welfare and other types of agencies (e.g. Bai et al., 2009; Hurlburt et al., 2004), the current study did not find significant associations between child welfare and juvenile justice connectivity and crossover youths' odds of receiving necessary behavioral health services. Previous studies that have found significant associations between interagency collaboration and youth behavioral health service receipt have focused on inter-organizational arrangements between child welfare and behavioral health providers (e.g. Cottrell, Lucey, Porter, \& Walker, 2000), not between child welfare and juvenile justice agencies. Therefore, this finding could reflect a genuine lack of association with youth behavioral health service receipt.

However, it is also possible that the measure of connectivity used within this study did not accurately capture the extent to which agency staff participated in these inter-organizational arrangements. Network analysis has demonstrated that cooperative relationships between child welfare and juvenile justice agencies tend to develop incrementally over time (Rivard, Johnsen, Morrissey, \& Starrett, 1999). Child welfare agency director reports of the presence of such ties may not capture the strength of personal relationships between staff or the amount of day-today communications that actually occurred. In support of this possibility, a recent study examining collaboration between child welfare and substance abuse treatment agencies found that some front line workers within each agency were more likely to engage in interagency collaboration than others (Smith \& Mogro-Wilson, 2007); the study also found that administrators' reports of collaborative practices did not align with those reported by frontline staff. Future research examining how and when different types of inter-organizational arrangements between staff at child welfare and juvenile justice agencies influence youth service receipt could clarify this issue.

The control variable finding of the greatest potential interest to policy makers may be that, compared to youth with public insurance, youth with private insurance had significantly lower odds of receiving inpatient treatment. While these findings could result from differences in youth service needs, they could also reflect efforts on the part of private insurance carriers to monitor and contain specialty behavioral health care usage and costs. In the last decade, private financing for substance abuse treatment has remained flat, while the role of public financing for mental health and substance abuse treatment has grown (Mark, Levit, Buck, Coffey, \& Vandivort-Warren, 2007; Mark, Levit, VandivortWarren, Caffey, \& Buck, 2007), resulting in an increased role for states in shaping the future of behavioral health care. Youth covered by public insurance may also find it easier to access behavioral health services because of federal requirements that the needs of children and youth identified through Early and Periodic Screening and Detection be addressed, even if those services are not generally covered through Medicaid (Rosenbaum \& Wise, 2007; Rubin, Halfon, Raghavan, \& Rosenbaum, 2005). Future research could address this issue in more depth. However, it will be interesting to see if private insurance disadvantage found in this paper persists as the 2008 federal legislation mandating parity in private coverage of mental and physical health care is implemented (Glied \& Frank, 2008). 


\subsection{Limitations}

There were a number of limitations to this study that must be considered in the interpretation of results. First, substantial listwise deletion resulted in an analytic sample that was not fully representative of the referent populations of children and child welfare agencies. The final sample over-represented youth who were sexually abused as well as those placed out-of-home. At the agency level, those serving a greater percentage of youth in out-of-home care were also over-represented. Sexual abuse and out-of-home placement are risk factors for youth behavioral health problems (Aarons et al., 2010). Although additional analyses did not reveal significant differences in youth behavioral health needs between included or excluded cases at either the individual or child welfare agency level, it is possible that the over-representation of sexually abused and out-of-home youth influenced the generality of these results to the overall population of crossover youth.

Second, even though prior evidence suggests that improved service access does not necessarily yield better clinical outcomes (Bickman, 1996), the NSCAW data only measured whether youth received services, not their duration, intensity, or appropriateness. The questions about youth behavioral health services also did not specify modality, which previous research has shown to predict treatment outcomes (Chamberlain, Leve, \& DeGarmo, 2007; Fisher \& Chamberlain, 2000; Henggeler, Clingempeel, Brondino, \& Pickrel, 2002; Henggeler, Melton, $\&$ Smith, 1992). In addition, if the effect size of any particular facet of collaboration - such as the total number of inter-organizational arrangements - was small, then the current study lacked statistical power to detect the association. Large confidence intervals for some covariates indicate measurement imprecision for some factors, possibly due to sampling issues, such as the relatively small number of youth in the sample described as Hispanic.

Finally, both person and agency-level data on child welfare-juvenile justice connections were limited. The sample was restricted to youth who had behavioral health needs and either court involvement or activities that were likely to create court involvement. However, not all of these youth were necessarily involved with both the behavioral health and juvenile justice systems. At the agency level, data on child welfare and juvenile justice agency collaboration were collected only once, at baseline. The cross-sectional nature of the data did not permit a more in-depth examination of inter-agency collaboration and how it may have evolved over time.

Despite the limitations described above, these are currently the only national data available to examine the questions addressed in this study. In recent years, professionals and policymakers have increasingly recognized the need to improve service experiences and outcomes for crossover youth (Morris \& Freundlich, 2004). However, the lack of available data impedes understanding of how factors such as inter-agency collaboration might improve service experiences and outcomes for these youth. The current study cannot establish causality, but does indicate some possible effects that merit additional research. Future research should include other methods such as case studies that incorporate the perspectives of both child welfare and juvenile justice agencies and examine how inter-agency coordination and outcomes unfold for individual youth across time in different local service contexts.

\subsection{Conclusion}

This study is one of the first to examine empirically the influence of interagency collaboration between child welfare and juvenile justice agencies on crossover youths' odds of receiving necessary behavioral health services. The current study found that designating a single agency as responsible for youths' care and linking administrative databases were associated with youth odds of receiving behavioral health services. These findings suggest that jurisdiction and shared information systems are important dimensions of interagency collaboration. These two dimensions of collaboration are currently under-examined in the empirical literature. Future 
efforts to improve service coordination for youth involved with multiple sectors could benefit from additional attention to agency accountability and operating systems.

\section{References}

Aarons G, James S, Monn A, Raghavan R, Wells R, Leslie L. Behavior problems and placement change in a national child welfare sample: A prospective study. Journal of the American Academy of Child and Adolescent Psychiatry 2010;49(1):70-80. [PubMed: 20215928]

Achenbach, T.; Edelbrock, C. Manual for the child behavior checklist and revised child behavior profile. University of Vermont, Department of Psychiatry; Burlington: 1983.

Altshuler S. From barriers to successful collaboration: Public schools and child welfare working together. Social Work 2003;48(1):52-63. [PubMed: 12564707]

Ascher B, Farmer E, Burns B, Angold A. The child and adolescent services assessment (CASA): Description and psychometrics. Journal of Emotional and Behavioral Disorders 1996;4:12-20.

Bagley C, Wood M, Wood L. Victim to abuser: Mental health and behavioral sequels of child sexual abuse in a community survey of young adult males. Child Abuse \& Neglect 1994;18(8):683-697. [PubMed: 7953908]

Bai Y, Wells R, Hillemeier M. Coordination between child welfare agencies and mental health service providers, children's service use, and outcomes. Child Abuse \& Neglect 2009;33:372-381. [PubMed: 19473702]

Baltodano H, Mathur S, Rutherford R. Transition of incarcerated youth with disabilities across systems and into adulthood. Exceptionality 2005;13(2):103-124.

Bardach, E. Getting agencies to work together: The practice and theory of managerial craftsmanship. Brookings Institution Press; Washington DC: 1998.

Barnes L, Bennett D, Bryson C, Diehl S, Hayes T, Anne C, et al. Tennessee's youth in juvenile justice facilities: Mental health and substance abuse issues. California Journal of Health Promotion 2005;3:144-158.

Beale, C. Measuring rurality: Rural-urban continuum codes. 2003. Retrieved October 10, 2003 from http://www.ers.usda.gov/Briefing/RuralUrbCon/.

Beitchman J, Zucker K, Hood J, DaCosta G, Akman D, Cassavia E. A review of the long-term effects of child sexual abuse. Child Abuse \& Neglect 1992;16(1):101-118. [PubMed: 1544021]

Bickman L. A continuum of care: More is not always better. American Psychologist 1996;51(7):689_ 701. [PubMed: 8694389]

Bilchik, S.; Stagner, M. Racial and ethnic disparity and disproportionality in child welfare and juvenile justice: A compendium. Chapin Hall Center for Children; Washington DC: 2009.

Blumberg E, Landsverk J, Ellis-MacLeod E, Ganger W, Culver S. Use of public mental health system by children in foster care: Client characteristics and service use patterns. Journal of Behavioral Health Services and Research 1996;23(4):389-405.

Brass D, Butterfield K, Skaggs B. Relationships and unethical behavior: A social network perspective. Academy of Management Review 1998;23(1):14-31.

Breda C. The mental health orientation of juvenile courts. Journal of Behavioral Health Services and Research 2001;28(1):89-95. [PubMed: 11330002]

Burns B, Costello E, Angold A, Tweed D, Stangl D, Farmer E, et al. Children's mental health service use across service sectors. Health Affairs 1995;14(3):147-159. [PubMed: 7498888]

Burns B, Phillips S, Wagner H, Barth R, Kolko D, Campbell Y, et al. Mental health need and access to mental health services by youths involved with child welfare: A national survey. Journal of the American Academy of Child \& Adolescent Psychiatry 2004;43(8):960. [PubMed: 15266190]

Cavaiola A, Schiff M. Behavioral sequelae of physical and/or sexual abuse in adolescents. Child Abuse \& Neglect 1988;12(2):181-188. [PubMed: 3395894]

Chamberlain P, Leve L, DeGarmo D. Multidimensional treatment foster care for girls in the juvenile justice system: 2-year follow-up of a randomized clinical trial. Journal of Consulting and Clinical Psychology 2007;75(1):187-193. [PubMed: 17295579] 
Cocozza J, Skowyra K. Youth with mental health disorders: Issues and emerging responses. Juvenile Justice Journal 2000;7(1):3-13.

Colby, S.; Murrell, W. Child welfare and substance abuse services: From barriers to collaboration. Sage Publications; Thousand Oaks, CA: 1998.

Coleman H, Jenson J. A longitudinal investigation of delinquency among abused and behavior problem youth following participation in a family preservation program. Journal of Offender Rehabilitation 2000;31(1-2):143-162.

Conger D, Ross T. Project Confirm: An outcome evaluation of a program for children in the child welfare and juvenile justice systems. Youth Violence and Juvenile Justice 2006;4(1):97.

Cottrell D, Lucey D, Porter I, Walker D. Joint working between child and adolescent mental health services and the department of social services: The Leeds model. Clinical Child Psychology and Psychiatry 2000;5(4):481.

Courtney M. Research needed to improve the prospects for children in out-of-home placement. Children and Youth Services Review 2000;22(9-10):743-761.

Courtney M, Barth R, Berrick J, Brooks D, Needell B, Park L. Race and child welfare services: past research and future directions. Child Welfare 1996;75(2):99-137. [PubMed: 8901382]

Darlington Y, Feeney J, Rixon K. Interagency collaboration between child protection and mental health services: Practices, attitudes and barriers. Child Abuse \& Neglect 2005;29(10):1085-1098. [PubMed: 16315352]

DeLeeuw, J.; Meijer, E. Handbook of Multilevel Analysis. Springer Verlag; 2008.

Dowd, K.; Kinsey, S.; Wheeless, S.; Thissen, R.; Richardson, J.; Suresh, R., et al. National Survey of Child and Adolescent Well-being (NSCAW) Combined waves 1-4. Data file users manual general release version. National Data Archive on Child Abuse and Neglect; Ithaca, New York: 2004.

Drabble L. Pathways to collaboration: Exploring values and collaborative practices between child welfare and substance abuse treatment fields. Child Maltreatment 2007;12(31-42)

Elliott D, Ageton S. Reconciling differences in self-reported and official estimates of delinquency. American Sociological Review 1980;45:95-110.

Fedoravicius N, McMillen J, Rowe J, Kagotho N, Ware N. Funneling child welfare consumers into and through the mental health system: Assessment, referral, and quality issues. Social Service Review 2008;82(2):273-290.

Fisher P, Chamberlain P. Multidimensional treatment foster care. Journal of Emotional and Behavioral Disorders 2000;8(3):155-164.

Glascoe F. Early detection of developmental and behavioral problems. Pediatrics in Review 2000;21(8): 272-280. [PubMed: 10922024]

Glied S, Frank R. Shuffling towards parity: Bringing mental health care under the umbrella. New England Journal of Medicine 2008;359(2):113-115. [PubMed: 18614779]

Glied S, Hoven C, Moore R, Garrett A, Regier D. Children's access to mental health care: does insurance matter? Health Affairs 1997;16(1):167-174. [PubMed: 9018954]

Glisson C. Judicial and service decisions for children entering state custody: The limited role of mental health. Social Service Review 1996;70(2):257-281.

Glisson C, Hemmelgarn A. The effects of organizational climate and interorganizational coordination on the quality and outcomes of children's service systems. Child abuse \& neglect 1998;22(5):401-421. [PubMed: 9631252]

Goldstrom I, Jaiquan F, Henderson M, Male A, Manderscheid R. The availability of mental health services to young people in juvenile justice facilities: A national survey. Mental Health, United States 2001;2000:248-268.

Granovetter M. The strength of weak ties. American Journal of Sociology 1973;6:1360-1380.

Graves K, Frabutt J, Shelton T. Factors associated with mental health and juvenile justice involvement among children with serious emotional disturbance. Youth Violence and Juvenile Justice 2007;5:147-167.

Gray, B. Assessing inter-organizational collaboration: Multiple conceptions and multiple methods. In: Faulkner, D.; DeRond, M., editors. Cooperative strategy: Economic, business, and organizational issues. Oxford University Press; New York: 2000. p. 243-260. 
Greenbaum P, Dedrick R, Friedman R, Kutash K, Brown E, Lardieri S, et al. National Adolescent and Child Treatment Study (NACTS): Outcomes for children with serious emotional and behavioral disturbance. Journal of Emotional and Behavioral Disorders 1996;4(3):130.

Halemba, G.; Siegel, G.; Lord, R.; Zawacki, S. Arizona dual jurisdiction study: Final report. National Center for Juvenile Justice; Pittsburgh: 2004.

Heggeness M, Davis E. Factors influencing length of stay in out-of-home placements: Are human services and corrections placements different? Children and Youth Services Review 2010;32(5):749-757.

Henggeler S, Clingempeel W, Brondino M, Pickrel S. Four-year follow-up of multisystemic therapy with substance abusing and dependent juvenile offenders. Journal of the American Academy of Child and Adolescent Psychiatry 2002;41:868-874. [PubMed: 12108813]

Henggeler S, Melton G, Smith L. Family preservation using multisystemic therapy: An effective alterantive to incarcerating serious juvenile offenders. Journal of Consulting and Clinical Psychology 1992;60:953-961. [PubMed: 1460157]

Herz D, Krinsky M, Ryan J. Improving system responses to crossover youth: The role of research and practice partnerships. Child Welfare League of America - Connecting Juvenile Justice and Child Welfare 2006;5(1)

Herz, D.; Ryan, J. Building multisystem approaches in child welfare and juvenile justice. Casey Family Programs; 2008.

Howell J, Kelly M, Palmer J, Mangum R. Integrating child welfare, juvenile justice, and other agencies in a continuum of services. Child Welfare 2004;83(2):143-156. [PubMed: 15068216]

Hunter T. Child welfare and alcohol and other drug treatment: Bridging the gap to comprehensive services. Journal of Family Social Work 2003;74(4):63-73.

Hurlburt M, Leslie L, Landsverk J, Barth R, Burns B, Gibbons R, et al. Contextual predictors of mental health service use among children open to child welfare. Archives of General Psychiatry 2004;61 (12):1217-1224. [PubMed: 15583113]

Ibarra H. Personal networks of women and minorities in management: A conceptual framework. Academy of Management Review 1993;18(1):56-87.

Ibarra H. Race, opportunity, and diversity of social circles in managerial networks. Academy of Management Journal 1995;38(3):673-703.

Jonson-Reid M. Exploring the relationship between child welfare intervention and juvenile corrections involvement. American Journal of Orthopsychiatry 2002;72(4):559-576. [PubMed: 15792041]

Jonson-Reid M, Barth R. From maltreatment report to juvenile incarceration: The role of child welfare services. Child Abuse \& Neglect 2000;24(4):505-520. [PubMed: 10798840]

Kamradt B. Wraparound Milwaukee: Aiding youth with mental health needs. Juvenile Justice Journal 2000;7(1):14-23.

Kolko D, Herschell A, Costello A, Kolko R. Child welfare recommendations to improve mental health services for children who have experienced abuse and neglect: A national perspective. Administration and Policy in Mental Health and Mental Health Services Research 2009;36:50-62. [PubMed: 19127426]

Kortenkamp, K.; Ehrle, J. The well-being of children involved with the child welfare system: A national overview. The Urban Institute; Washington, DC: 2002. Series B, No. B-43

Leslie L, Gordon J, Meneken L, Premji K, Michelmore K, Ganger W. The physical, developmental, and mental health needs of young children in child welfare by initial placement type. Journal of Developmental and Behavioral Pediatrics 2005;26(3):177. [PubMed: 15956866]

Libby A, Kelleher K, Leslie L, O'Connell J, Wood P, Rolls J, et al. Child welfare systems policies and practices affecting Medicaid health insurance for children: A national study. Journal of Social Service Research 2007;33(2):39-49.

Little R. Missing-data adjustments in large surveys. Journal of Business and Economic Statistics 1988;6 (3):287-301.

Malmgren K, Meisel S. Examining the link between child maltreatment and delinquency for youth with emotional and behavioral disorders. Child Welfare 2004;83(2):175-188. [PubMed: 15068218]

Mark T, Levit K, Buck J, Coffey R, Vandivort-Warren R. Mental health treatment expenditure trends, 1986-2003. Psychiatric Services 2007;58(8):1041-1048. [PubMed: 17664514] 
Mark T, Levit K, Vandivort-Warren R, Caffey R, Buck J. Trends in spending for substance abuse treatment, 1986-2003. Health Affairs 2007;26(4):1118-1128. [PubMed: 17630455]

Morris, L.; Freundlich, M. Youth involvement in the child welfare and juvenile justice systems: A case of double jeopardy?. Child Welfare League of America Press; Washington DC: 2004.

Nash M, Bilchik S. Child welfare and juvenile justice: Two sides of the same coin, part 2. Juvenile and Family Justice Today 2009:22-25.

Ostrom, E. Governing the commons: The evolution of institutions for collective action. Cambridge University Press; Cambridge, England: 1990.

Polivka B, Clark J. A collaborative system of care for youth with severe emotional disturbances: An evaluation of client characteristics and services. Journal of Mental Health Administration 1994;21 (2):170-184. [PubMed: 10133778]

Pullmann M, Kerbs J, Koroloff N, Veach-White E, Gaylor R, Sieler D. Juvenile offenders with mental health needs: Reducing recidivism using wraparound. Crime \& Delinquency 2006;52(3):375.

Raghunathan, T.; Solenberger, P.; Hoewyk, J. IVEware: Imputation and variance estimation software user guide. Survey Methodology Program at the Survey Research Center Institute for Social Research at the University of Michigan; Ann Arbor, Michigan: 2002.

Raudenbush, S.; Bryk, A. Hierarchical linear models: Applications and data analysis methods. Sage; Thousand Oaks, CA: 2002.

Rittner B. Effects of court-ordered substance abue treatment in child protective services cases. Social Work 2000;45(2):131-140. [PubMed: 10710986]

Rivard J, Johnsen M, Morrissey J, Starrett B. The dynamics of interagency collaboration: How linkages develop for child welfare and juvenile justice sectors in a system of care demonstration. Journal of Social Service Research 1999;25(3):61-82.

Rosenbaum S, Wise P. Crossing the Medicaid-private insurance divide: The case of EPSDT. Health Affairs 2007;26(2):382. [PubMed: 17339664]

Ross, T. Child welfare: challenges of collaboration. Urban Institute Press; Washington DC: 2009.

Rubin, D.; Halfon, N.; Raghavan, R.; Rosenbaum, S. Protecting children in foster care: Why proposed Medicaid cuts harm our nation's most vulnerable youth. Casey Family Programs; Washington, DC: 2005.

Ryan J, Herz D, Hernandez P, Marshall J. Maltreatment and delinquency: Investigating child welfare bias in juvenile justice processing. Children and Youth Services Review 2007;29(8):1035-1050.

SAMHSA. Results from the 2007 National Survey on Drug Use and Health: National Findings. Substance Abuse and Mental Health Services Administration, Office of Applied Studies; Rockville, MD: 2008. DHHS Publication No. SMA 08-4343

Schwartz, I. Juvenile crime: the youth corrections agenda for the 1990s. In: Russell, C.; McCauley, C., editors. Crime and justice in the 1990s. Vanderbilt Institute for Public Policy Studies; Nashville, TN: 1989. p. 45-50.

Sedlak A, Schultz D, Wells S, Lyons P, Doueck H, Gragg F. Child protection and justice systems processing of serious child abuse and neglect cases. Child Abuse \& Neglect 2006;30(6):657-677. [PubMed: 16782193]

Siegel G, Lord R. When systems collide: Improving court practices and programs in dual jurisdiction cases. Juvenile and Family Court Journal 2005;56:39-59.

Smith B, Mogro-Wilson C. Multi-level influences on the practice of inter-agency collaboration in child welfare and substance abuse treatment. Children and Youth Services Review 2007;29(5):545-556.

Spybrook J, Raudenbush S, Liu X, Congdon R, Martinez A. Optimal Design for longitudinal and multilevel research: Documentation for the "Optimal Design" software. 2008

StataCorp, L. Users Guide: Version 9.0. Stata Press; College Station, TX: 2005.

StataCorp, L. Stata statistical software: Release 10.0. Stata Corporation; College Station, TX: 2007.

Stiffman A, Chen Y, Elze D, Dore P, Cheng L. Adolescents' and providers' perspectives on the need for and use of mental health services. Journal of Adolescent Health 1997;21(5):335-342. [PubMed: 9358297]

Thomas K, Ellis A, Konrad T, Holzer C, Morrissey J. County-level estimates of mental health professional shortage in the United States. Psychiatric Services 2009;60(10):1323. [PubMed: 19797371] 
Thomson A, Perry J, Miller T. Conceptualizing and measuring collaboration. Journal of Public Administration Research and Theory 2007;19:23-56.

Thornberry T, Huizinga D, Loeber R. The causes and correlates studies: Findings and policy implications. Juvenile Justice 2004;9(1):3-19.

Tjaden P, Thoennes N. Predictors of legal intervention in child maltreatment cases. Child Abuse \& Neglect 1992;16:807-821. [PubMed: 1486510]

Vander Stoep A, Evens C, Taub J. Risk of juvenile justice system referral among children in a public mental health system. Journal of Behavioral Health Services and Research 1997;24(4):428-442.

Wagner F, Anthony J. Into the world of illegal drug use: Exposure, opportunity and other mechanisms linking the use of alcohol, tobacco, marijuana, and cocaine. American Journal of Epidemiology 2002;155(10):918. [PubMed: 11994231]

Wall A, Kohl P. Substance use in maltreated youth: Findings from the National Survey of Child and Adolescent Well-Being. Child Maltreatment 2007;12(1):20-30. [PubMed: 17218645]

Widom C. Child abuse, neglect, and violent criminal behavior. Criminology 1989;27:251.

Wiig, J.; Widom, C. Understanding child maltreatment and juvenile delinquency. From research to effective program, practice, and systemic solutions. Child Welfare League of America Press; Washington DC: 2003.

Young N, Boles S, Otero C. Parental substance use disorders and child maltreatment: Overlaps, gaps, and opportunities. Child Maltreatment 2007;12(2):137-149. [PubMed: 17446567] 
Table 1

Descriptive Statistics ( $\mathrm{N}=178$ youth within 51 agencies)

\begin{tabular}{|c|c|c|c|c|}
\hline & $\begin{array}{l}\text { Weighted } \\
\text { Mean/ \% }\end{array}$ & Std Error & Min & Max \\
\hline \multicolumn{5}{|l|}{ Behavioral health service receipt } \\
\hline Did not receive any behavioral health services & $20 \%$ & -- & 0 & 1 \\
\hline Outpatient mental health & $78 \%$ & -- & 0 & 1 \\
\hline Inpatient mental health & $33 \%$ & -- & 0 & 1 \\
\hline Outpatient substance abuse & $14 \%$ & -- & 0 & 1 \\
\hline Inpatient substance abuse & $13 \%$ & -- & 0 & 1 \\
\hline \multicolumn{5}{|l|}{ Collaboration between child welfare and juvenile justice } \\
\hline Jurisdiction: joint control (referent) & $22 \%$ & -- & 0 & 1 \\
\hline Jurisdiction: child welfare only & $36 \%$ & -- & 0 & 1 \\
\hline Jurisdiction: juvenile justice only & $42 \%$ & -- & 0 & 1 \\
\hline Information systems: extent of data sharing & 0.21 & 0.53 & 0 & 2 \\
\hline Connectivity: number of inter-agency ties & 3.63 & 0.25 & 0 & 5 \\
\hline \multicolumn{5}{|l|}{ Control variables } \\
\hline Non-metropolitan location & $21 \%$ & -- & 0 & 1 \\
\hline Local provider availability: $\%$ unmet mental health need & 22.30 & 2.36 & 0 & 63 \\
\hline Local provider availability: \# of behavioral health facilities & 19.91 & 4.11 & 1 & 266 \\
\hline Court ordered services & $34 \%$ & -- & 0 & 1 \\
\hline Comorbidity: substance abuse problem & $61 \%$ & -- & 0 & 1 \\
\hline Comorbidity: mental health problem & $75 \%$ & -- & 0 & 1 \\
\hline Type of maltreatment: neglect or non-sexual abuse (referent) & $79 \%$ & -- & 0 & 1 \\
\hline Type of maltreatment: sexual abuse & $21 \%$ & -- & 0 & 1 \\
\hline Out-of-home placement & $31 \%$ & -- & 0 & 1 \\
\hline Child is male & $50 \%$ & -- & 0 & 1 \\
\hline Child age in years & 12.95 & 0.21 & 6 & 16 \\
\hline Child is African American & $26 \%$ & -- & 0 & 1 \\
\hline Child is Hispanic & $9 \%$ & -- & 0 & 1 \\
\hline Child insurance: public (referent) & $75 \%$ & -- & 0 & 1 \\
\hline Child insurance: private & $19 \%$ & -- & 0 & 1 \\
\hline Child insurance: self-pay & $6 \%$ & -- & 0 & 1 \\
\hline
\end{tabular}




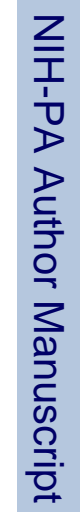

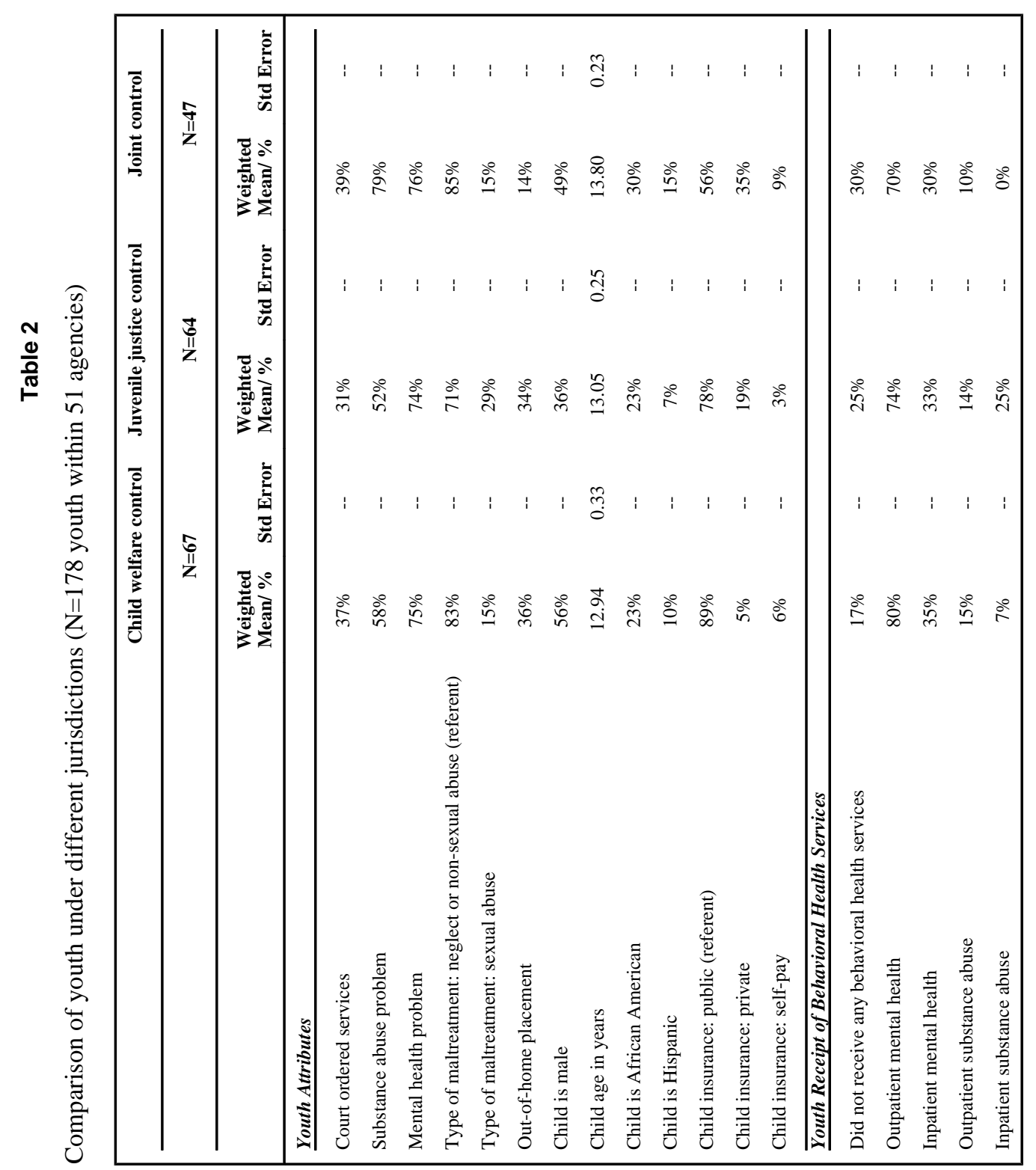

Child Youth Serv Rev. Author manuscript; available in PMC 2011 December 1. 


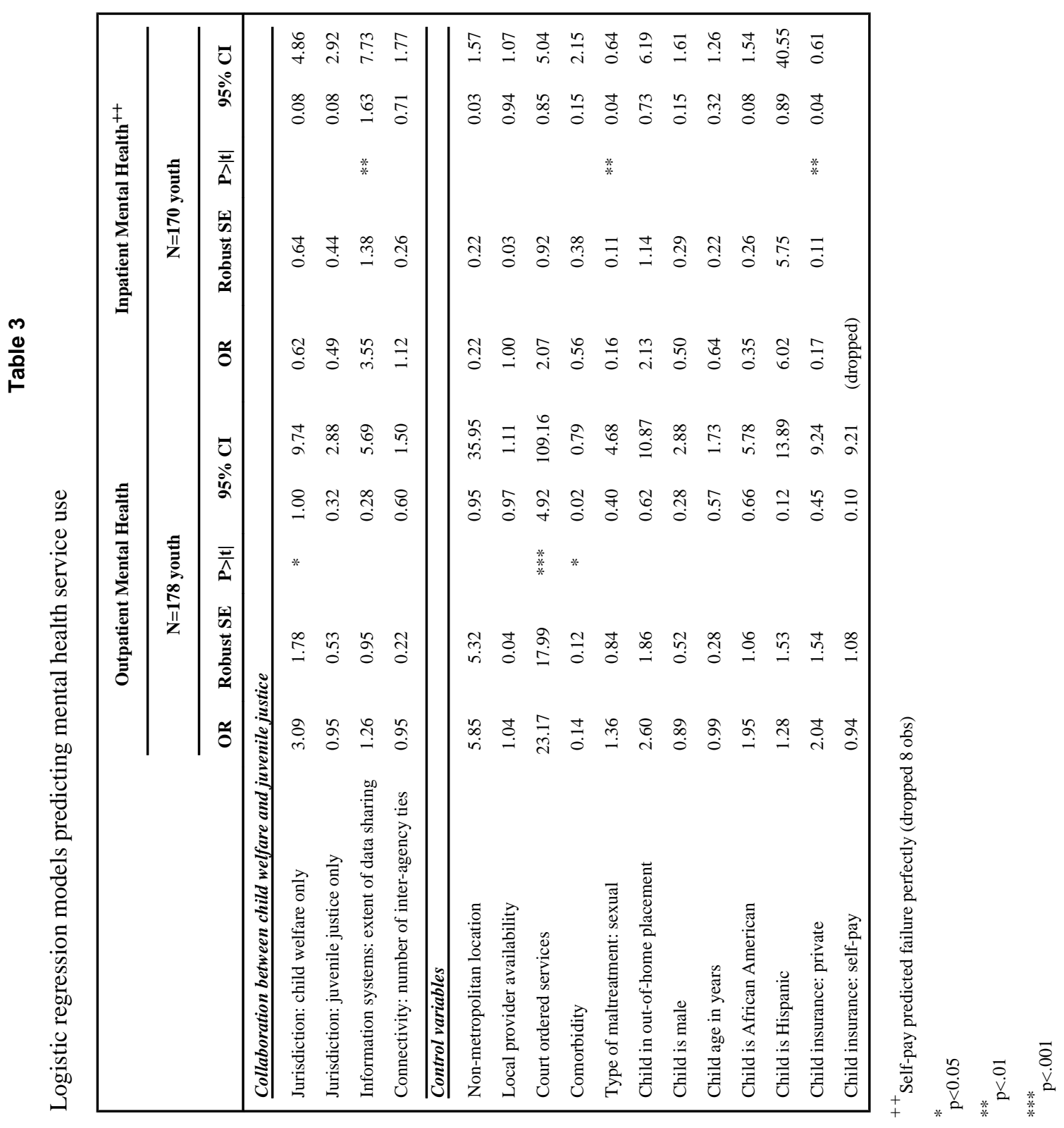

Child Youth Serv Rev. Author manuscript; available in PMC 2011 December 1. 


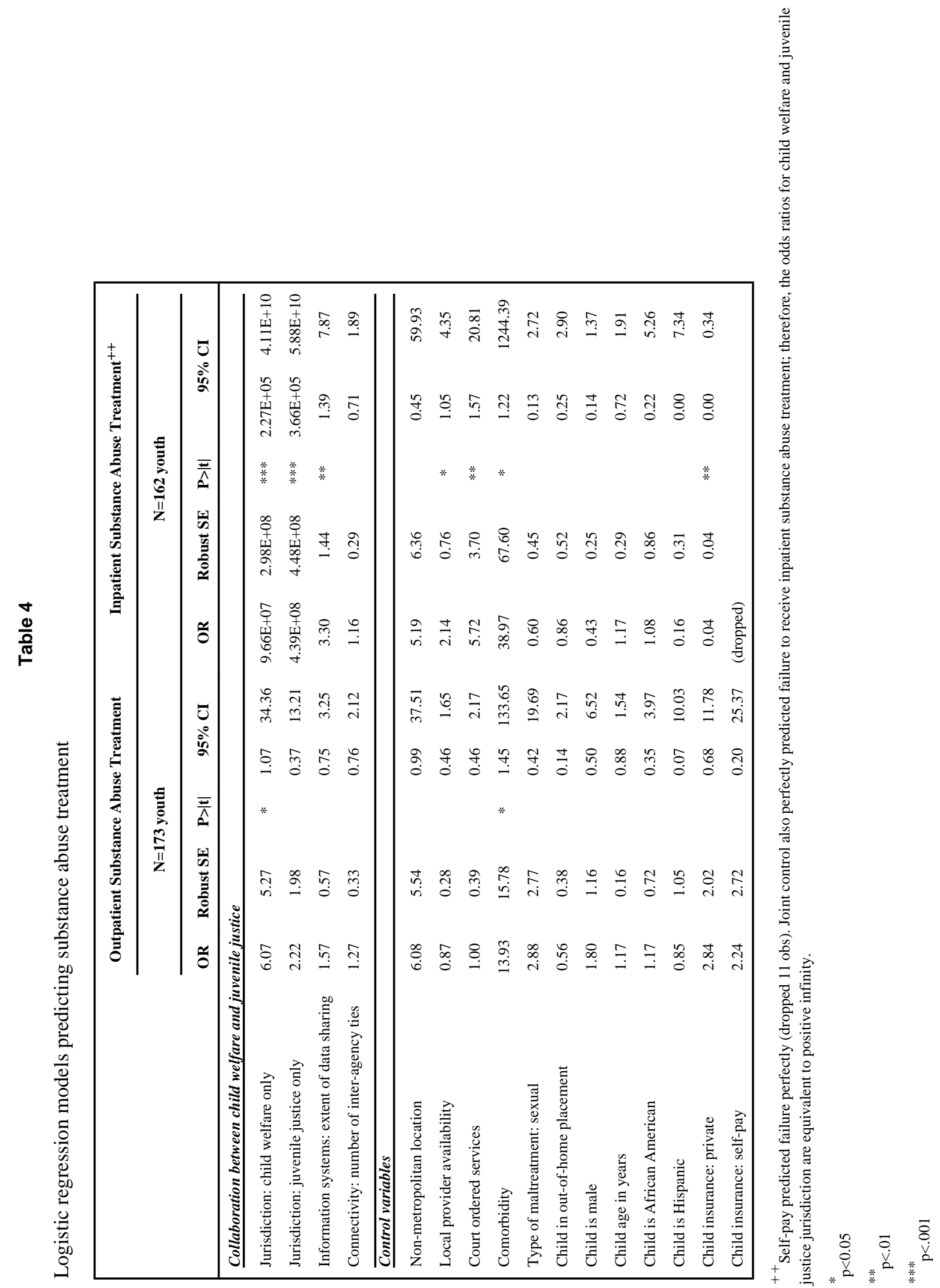

Child Youth Serv Rev. Author manuscript; available in PMC 2011 December 1. 